\title{
Transcription Factor GATA-6 Is Expressed in Malignant Endoderm of Pediatric Yolk Sac Tumors and in Teratomas
}

\author{
SUSANNA SILTANEN, PÄIVI HEIKKILÄ, MALGORZATA BIELINSKA, DAVID B. WILSON, AND \\ MARKKU HEIKINHEIMO \\ Children's Hospital and Program for Developmental and Reproductive Biology, Biomedicum [S.S., M.H.], \\ Department of Pathology [P.H.], University of Helsinki, 00290 Helsinki, Finland, and Departments of \\ Pediatrics [D.B.W., M.B., M.H.] and Molecular Biology and Pharmacology [D.B.W.], Washington \\ University School of Medicine, St. Louis, Missouri 63110, U.S.A.
}

\begin{abstract}
Transcription factors GATA-4 and GATA-6 play critical roles in mammalian yolk sac differentiation and function. Previously, we showed that GATA-4 is a potential marker for malignant yolk sac endoderm in pediatric germ cell tumors. This highly malignant tissue can cause diagnostic problems because yolk sac components may be difficult to differentiate from other, especially immature, tissue types in teratomas. In the search for new molecular markers for germ cell tumors, we have surveyed GATA-6 expression in benign and malignant pediatric germ cell tumors using mRNA in situ hybridization and immunohistochemistry. GATA-6 was expressed in most yolk sac tumors examined and also in nonmalignant tissues including gut/ respiratory epithelium, sebocytes, and neuroepithelium in mature and immature teratomas. Given that GATA- 6 has not been
\end{abstract}

\section{ABSTRACT}

discovered in sebocytes before, this finding was confirmed by immunohistochemistry of normal mouse samples, indicating a function for this transcription factor in the mammalian skin. Taken together, GATA-6 can be used to identify yolk sac components in pediatric germ cell tumors. Furthermore, it is also expressed in specific tissues in teratomas. GATA-6, together with GATA-4, can thus be used as a novel molecular marker in characterizing of pediatric germ cell tumors. (Pediatr Res 54: 542-546, 2003)
AFP, $\alpha$-fetoprotein
YST, yolk sac tumor
GCT, germ cell tumor

\section{Abbreviations}

germ cell migration or imbalance in the hormonal milieu of the developing gonad may render early germ cells prone to neoplastic transformation (2).

Germ cells may give rise to tumors at any point in their migration path or at any stage of their differentiation. The pluripotential cells can differentiate into various embryonic or extraembryonic tissues, which in turn may be either benign or malignant. GCT commonly contain a mixture of benign and malignant components, which creates diagnostic challenges. The term teratoma is used to describe both benign and malignant tumors composed of haphazardly intermixed tissues from all three embryonic germ layers that are foreign to the anatomic site in which they arise. These tumors are subclassified into mature teratomas, which consist of well-differentiated adulttype tissues, and immature teratomas, which contain embryonic tissues, such as neural rosettes, metanephric blastema, or endochondral ossification foci.

YST, also known as endodermal sinus tumor, is the most common malignant GCT of childhood. YST resemble murine yolk sac by their labyrinthine histology and contain SchillerDuval bodies, which are endoderm-lined cavities supported by 
loose stroma. These tumors usually produce AFP that can be detected in the tumor tissue and blood (3); serum AFP is a commonly used marker in the diagnostics and follow-up of these tumors.

Two members of the GATA family of transcription factors, GATA-4 and GATA- 6 , have been implicated in the mammalian yolk sac endoderm differentiation and function. Both of these factors are expressed in the visceral and parietal yolk sac endoderm of rodents $(4,5)$. Gata6 $-/-$ mice die by embryonal d 7.5 and the extraembryonic endoderm in these embryos is morphologically and functionally defective $(6,7)$. We have now extended these studies on the early mouse extraembryonic endoderm development to the entire fetal period. Based on these findings, we were interested in exploring the role of GATA-6 in pediatric GCT, often including endodermal derivatives. We find that GATA-6, like GATA-4, is expressed in malignant endoderm within pediatric YST. In addition, GATA-6 is also expressed in certain nonmalignant tissues (e.g. sebocytes and neuroepithelium) within mature and immature teratomas.

\section{MATERIALS AND METHODS}

Pediatric yolk sac tumors and teratomas. Paraformaldehyde-fixed, paraffin-embedded human tissue was originally collected for diagnostic purposes. The samples included nine yolk sac tumors (three gonadal and six extragonadal), one embryonal carcinoma (vaginal), 16 benign teratomas (12 gonadal and four sacrococcygeal), and five immature teratomas (two gonadal and three extragonadal) (see Tables 1 and 2 for summary of the tumors studied). Serial sections $(5-8 \mu \mathrm{m})$ were stained with hematoxylin and eosin or subjected to mRNA in situ hybridization or immunohistochemistry for GATA-6. All tumor histology was reviewed by a designated pathologist (P.H.). The ethical committee of University of Helsinki approved the study.

Normal mouse yolk sac samples. Mouse embryos were obtained by mating male and female B6DJLF1/J or NMRI mice. For estimating embryonal age, noon of the day on which the copulation plug was found was considered as $0.5 \mathrm{~d}$ postconception (p.c.). Precise staging of dissected embryos was performed using The Atlas of Mouse Development (Academic Press, London). The yolk sacs and placentas from 6 to
14 d p.c. were collected together with the embryos and frozen or fixed in $4 \%$ paraformaldehyde and embedded in paraffin. All experiments on animals were performed according to the $\mathrm{Na}$ tional Research Council's guide.

$\boldsymbol{m} \boldsymbol{R} N \boldsymbol{A}$ in situ hybridization. The tissue sections from paraffin-embedded human tissue samples and frozen mouse embryos with the extraembryonic membranes and placenta were subjected to radioactive in situ hybridization as described previously (8). Mouse and human GATA-6 riboprobes were prepared as described elsewhere $(8,9)$. In brief, the tissue sections were incubated with $1 \times 10^{6} \mathrm{CPM}$ of $\left[{ }^{33} \mathrm{P}\right]$-labeled (1000-3000 Ci/mmol, Amersham Pharmacia Biotech, Piscataway, NJ, U.S.A.) antisense or sense riboprobe in a total volume of $80 \mu \mathrm{L}$.

Immunohistochemistry. The tissue sections from paraffinembedded human tissue samples and mouse embryos with the extraembryonic membranes and placenta were subjected to immunohistochemistry using a commercial polyclonal antimouse GATA-6 IgG (Santa Cruz Biotechnology, Santa Cruz, CA, U.S.A.) or nonimmune IgG as the primary antibody. A commercially available avidin-biotin immunoperoxidase system was used to visualize bound antibody (Vectastain Elite ABC Kit, Vector Laboratories, Burlingame, CA, U.S.A.). 3,3'Diaminobenzidine (Sigma Chemical, St. Louis, MO, U.S.A.) was used as the chromogen. The expression intensity in tumors was defined as - , if no expression was detected, and,+++ , or +++ if the proportion of positive cells in the tumor was less than $30 \%, 30-60 \%$, or more than $60 \%$, respectively (Table 1).

\section{RESULTS}

Mouse yolk sac endoderm expresses GATA-6 throughout embryonic development. Previous studies have documented that GATA-6 mRNA is expressed in the yolk sac endoderm of gastrulating mouse embryos $(5,6)$. We have now extended these studies by in situ hybridization and immunohistochemistry on a series of sections from developing mouse embryos from two mouse strains, B6DJLF1/J and NMRI, which yielded identical results. Consistent with earlier reports, GATA-6 mRNA and protein was found in the folding heart, the developing vessel smooth muscle, and the developing gut (data not shown). Abundant GATA-6 mRNA and protein was observed

Table 1. Characteristics of the patients with malignant germ cell tumors and levels of GATA-6 expression. The levels of GATA-4 and AFP expression are shown for comparison.

\begin{tabular}{|c|c|c|c|c|c|c|c|c|}
\hline \multirow{2}{*}{$\begin{array}{l}\text { Patient } \\
\text { no. }\end{array}$} & \multirow{2}{*}{$\begin{array}{l}\text { Age at diagnosis } \\
\text { (y) and sex }\end{array}$} & \multirow{2}{*}{$\begin{array}{l}\text { Outcome (years } \\
\text { after diagnosis) }\end{array}$} & \multicolumn{3}{|c|}{ Tumor } & \multicolumn{3}{|c|}{ Marker expression } \\
\hline & & & Localization & Histology & Metastasis & GATA-6 & GATA-4 & AFP \\
\hline 1 & $4.0 \mathrm{M}$ & NED (2) & Testis & YST & & +++ & + & + \\
\hline 2 & $1.6 \mathrm{M}$ & NED (8) & Pelvis & YST & & +++ & +++ & + \\
\hline 3 & $14.5 \mathrm{~F}$ & NED (14) & Ovary & YST & Omentum & +++ & + & + \\
\hline 4 & $2.5 \mathrm{~F}$ & NED (7) & Pelvis & YST & & - & +++ & ++ \\
\hline 5 & $11 \mathrm{~F}$ & NED (1) & Vagina & $\mathrm{EC}$ & & +++ & - & - \\
\hline 6 & $1.3 \mathrm{M}$ & Died (5) & Pelvis & YST & Lung & ++ & + & - \\
\hline 7 & $1.5 \mathrm{~F}$ & NED (2) & Pelvis & YST & & +++ & - & + \\
\hline 8 & $2.1 \mathrm{~F}$ & NED (1) & Pelvis & YST & Lung & ++ & ++ & + \\
\hline 9 & $1.0 \mathrm{M}$ & NED (7) & Testis & YST & & + & + & + \\
\hline 10 & $1.6 \mathrm{~F}$ & NED (16) & Pelvis & YST & & +++ & +++ & + \\
\hline
\end{tabular}

Abbreviations: NED, no evidence of disease; EC, embryonal carcinoma. 
Table 2. Expression of GATA-6 in benign and immature teratomas

\begin{tabular}{|c|c|c|c|c|c|c|c|c|c|}
\hline \multirow{3}{*}{$\begin{array}{l}\text { No. of } \\
\text { tumors }\end{array}$} & \multirow{3}{*}{$\begin{array}{l}\text { Average age } \\
\text { of the patients } \\
\text { at diagnosis }\end{array}$} & \multicolumn{2}{|c|}{ Tumor } & \multicolumn{6}{|c|}{ GATA-6 positivity (number of tumors positive indicated) } \\
\hline & & \multirow[b]{2}{*}{ Localization } & \multirow[b]{2}{*}{ Histology } & \multirow[b]{2}{*}{ Skin } & \multirow{2}{*}{$\begin{array}{c}\text { Sebaceous } \\
\text { gland }\end{array}$} & \multirow{2}{*}{$\begin{array}{l}\text { Resp. } \\
\text { epith. }\end{array}$} & \multirow[b]{2}{*}{ Gut } & \multicolumn{2}{|c|}{ Neural } \\
\hline & & & & & & & & Mature & Immature \\
\hline 8 & $8.5 \mathrm{y}$ & Ovary & Benign & 2 & 1 & 1 & 1 & 2 & 1 \\
\hline $4^{*}$ & $24.8 \mathrm{~d}$ & SCT & Benign & & & 1 & 1 & 1 & 1 \\
\hline 1 & $66 \mathrm{~d}$ & Testis & Immature & & & & & & \\
\hline 1 & $1 \mathrm{~d}$ & Abd. cavity & Immature & & & & & & \\
\hline
\end{tabular}

Abbreviations: SCT, sacrococcygeal teratoma; Abd. cavity, abdominal cavity; Resp. epith., tissue reminiscent of respiratory epithelium; Gut, tissue reminiscent of mature gut epithelium.

* Three patients, one residual tumor.

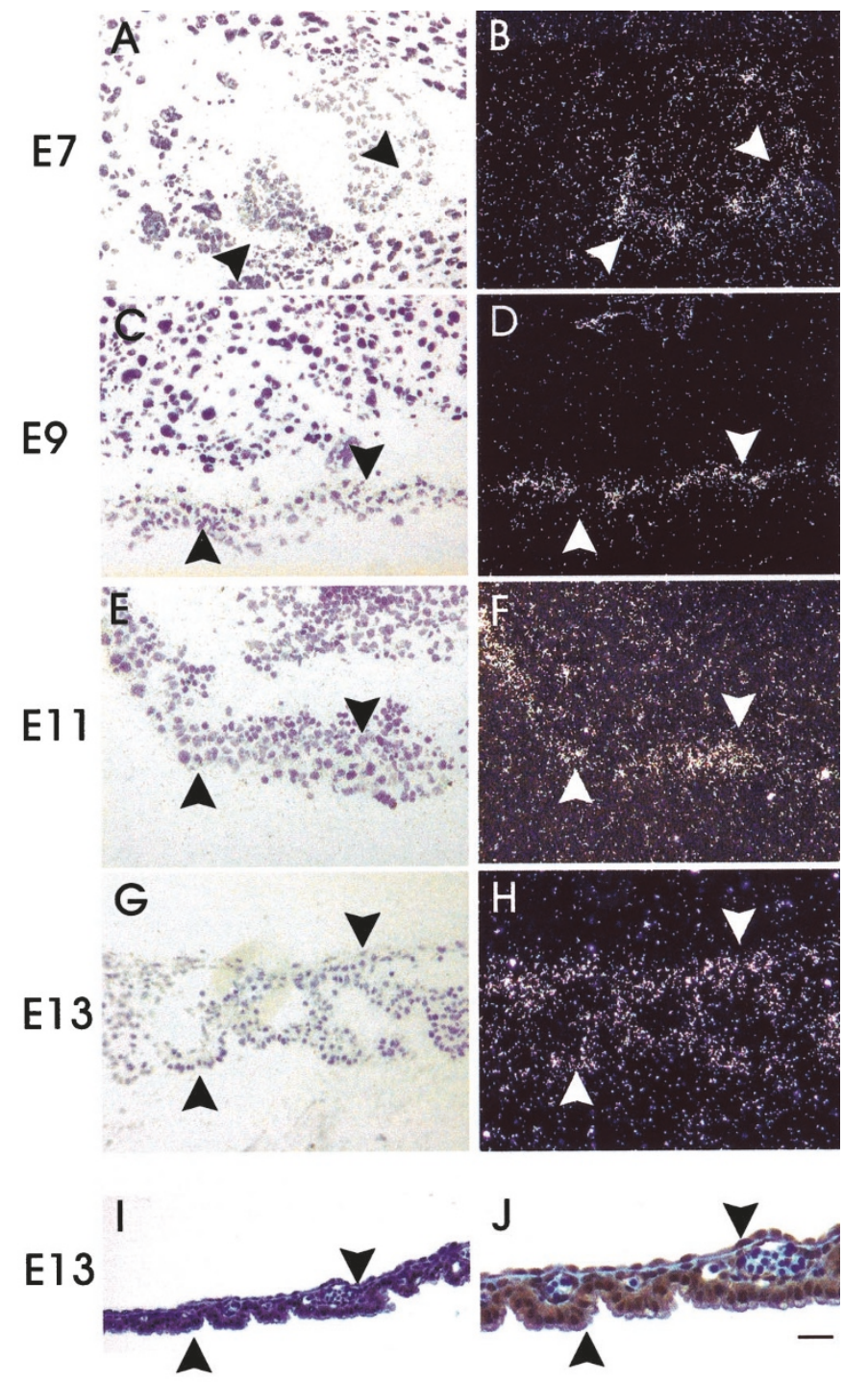

Figure 1. mRNA in situ hybridization and immunohistochemistry for GATA-6 in mouse embryos. Corresponding in situ hybridization bright field $(A, C, E, G)$, dark field $(B, D, F, H)$, and immunohistochemistry $(I, J)$ are shown. $A$ and $B$ : section of embryonal d 7 embryo. $C$ and $D$ : section of embryonal d 9 embryo. $E$ and $F$ : section of embryonal d 11 embryo. $G-J$ : section of embryonal d 13 embryo. GATA- 6 is expressed in parietal and visceral endoderm of the developing embryos. Arrowheads, yolk sac endoderm. Original magnifications $\times 100(A-I)$ and $\times 200(J)$, bar corresponds to $50 \mu \mathrm{m}$ in $A-I$ and to $100 \mu \mathrm{m}$ in $J$. in the visceral and parietal endoderm of the mouse embryos throughout embryonal development until embryonal d 13.5 (Fig. 1).

Malignant pediatric germ cell tumors express GATA-6 $\boldsymbol{m} \boldsymbol{R} \boldsymbol{N} \boldsymbol{A}$ and protein. The expression of GATA-6 in malignant pediatric GCT, including one embryonal carcinoma and nine YST, was examined using a combination of mRNA in situ hybridization and immunohistochemistry. The clinical and laboratory characteristics of these tumors are summarized in Table
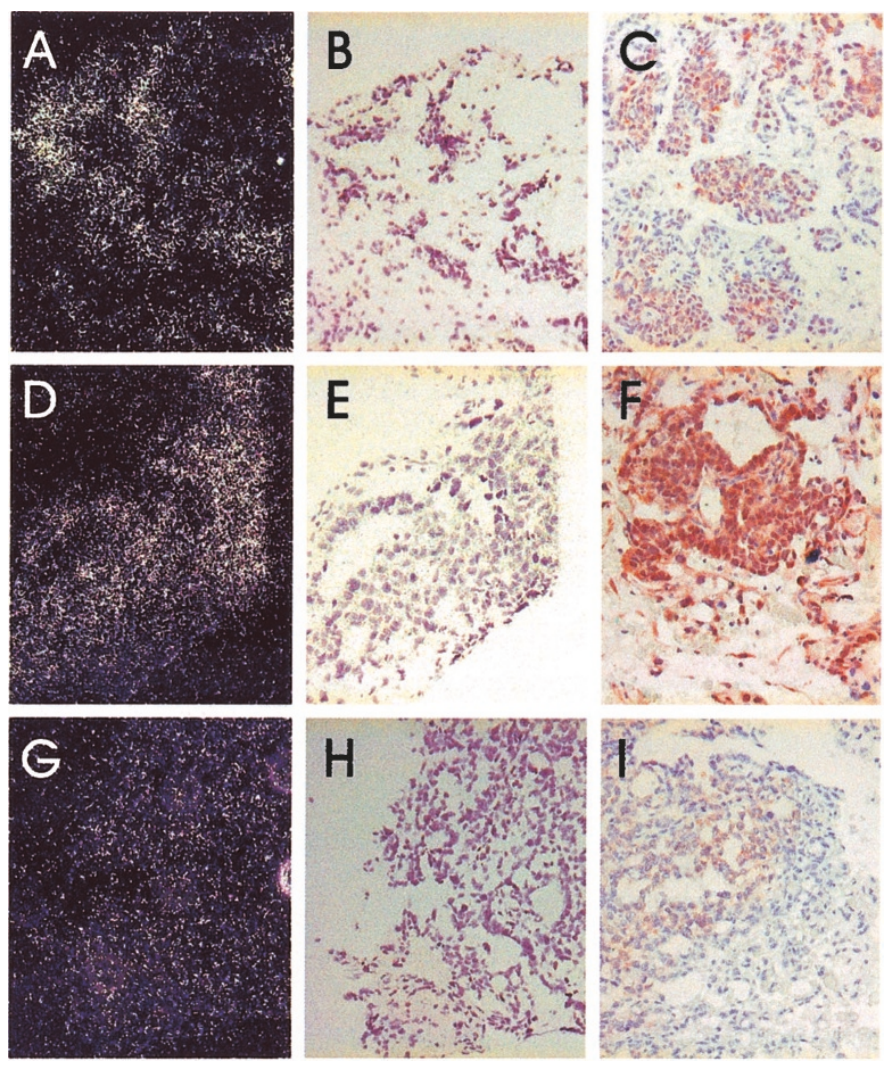

Figure 2. mRNA in situ hybridization and immunohistochemistry for GATA-6 in pediatric YST. Corresponding in situ hybridization dark field ( $A$, $D, G)$ and bright field $(B, E, H)$, and immunohistochemistry $(C, F, I)$ are shown. First row $(A-C)$ shows a GATA-6-positive area in a "highly positive" $(+++)$ pelvic YST (patient 2 from Table 1) and the second row $(D-F)$ a GATA-6-positive area in a "moderately positive" $(++)$ pelvic YST (patient 8 from Table 1). For comparison, a negative YST (patient 4 from Table 1) is shown in the third row $(G-I)$. Original magnification $\times 100$. 
1. The tumors examined were identical to those in our prior report (10), enabling a direct comparison of the expression of GATA- 6 and GATA-4 in these tumors.

Immunohistochemistry and mRNA in situ hybridization for GATA-6 yielded congruent results (Fig. 2). GATA-6 was found in nine of the 10 tumors studied, although the extent of expression varied among the tumors (Table 1). Abundant GATA-6 expression was detected in the embryonal carcinoma that lacked expression of GATA-4 (10). Within the YST, GATA-6 was detected in malignant yolk sac endoderm (Fig. 2) both in gonadal and extragonadal tumors. There was no obvious correlation between the expression of GATA- 6 and the expression of either GATA-4 or AFP (Table 1). We conclude that GATA-6 mRNA and protein are expressed in embryonal carcinoma and YST. Within malignant pediatric GCT, GATA-6 and GATA-4 exhibit overlapping, but not identical patterns of expression.

Specific tissues in mature and immature pediatric teratomas express GATA-6. To further characterize the expression of GATA-6 in pediatric GCT, we performed mRNA in situ hybridization and immunohistochemistry on a series of mature teratomas $(n=15)$ and immature teratomas $(n=5)$. The tumors studied were the same as in our previous report (10); their pathologic features are summarized in Table 2. By definition, none of these tumors contained any malignant yolk sac endoderm.

GATA-6 protein was detected in nine out of 17 mature teratomas, and localized to mature neural-type tissue, to goblet cells in epithelium reminiscent of gut or lung, and to structures closely resembling the appendages in skin (Fig. 3). In one of three testicular mature teratomas, scattered immature neural cells were found to be positive for GATA- 6 by mRNA in situ hybridization. Three of the five immature teratomas contained GATA-6 positive cells in cylindrical epithelium and neural blastomatous cells both by in situ hybridization and immunohistochemistry (Fig. 3, $A-C$ ). Thus, GATA-6 is expressed in a majority of mature and immature teratomas. Inasmuch as the expression of GATA-6 in normal mammalian skin has not been reported earlier, we wanted to confirm this finding on normal mouse skin. Using immunohistochemistry, we found strong nuclear staining for GATA-6 in the sebocytes of the skin appendages (Fig. 3, $G$ and $H$ ).

\section{DISCUSSION}

We have shown that GATA-6, a marker of yolk sac endoderm differentiation in mice, is also a marker of malignant endoderm differentiation in pediatric YST. In situ hybridization and immunohistochemical analyses suggest that the majority of human YST express GATA-6. GATA-6 and GATA-4 are co-expressed in both the developing murine yolk sac and most of the YST samples studied. Both these factors are vital for normal yolk sac development $(6,7,11-14)$, and recently it has been shown that forced expression of either GATA-6 or GATA-4 in embryonic stem cells triggers differentiation toward extraembryonic endoderm (15). Thus, the expression of these factors could well contribute to the malignant extraem-

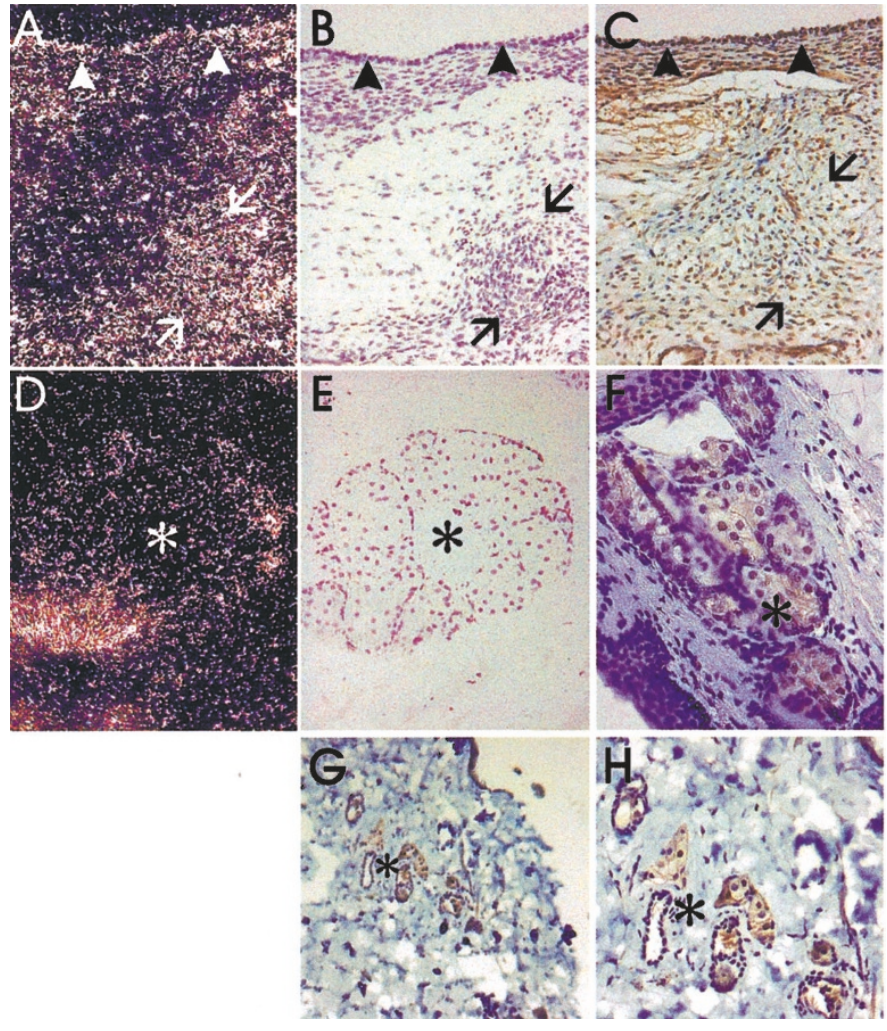

Figure 3. mRNA in situ hybridization and immunohistochemistry for GATA-6 in pediatric teratomas $(A-F)$ and immunohistochemistry for GATA-6 in normal mouse skin $(G, H)$. Corresponding in situ hybridization dark field $(A$, $D)$ and bright field $(B, E)$, and immunohistochemistry $(C, F)$ are shown. The first row $(A-C)$ shows cavities lined by goblet cell-like cells (arrowheads) and immature neural cells (arrows) in an immature teratoma. Note that these cells are positive in both in situ hybridization $(A, B)$ and immunohistochemistry $(C)$. The second row $(D-F)$ shows a positive sebaceous gland (asterisk) from the only mature teratoma that was GATA-6 positive in both in situ hybridization and immunohistochemistry. The third row $(G, H)$ shows immunohistochemistry on normal mouse skin; the nuclei of the cells in the sebaceous gland (asterisk) are GATA-6 positive. Original magnifications $\times 100(A-G)$ and $\times 200(H)$

bryonic endoderm differentiation of the activated primordial germ cells.

Although GATA-6 is a potentially useful antigen for pathologic classification of GCT, the presence of this marker is not pathognomonic for YST or other malignant germ cell neoplasms. This can be concluded given that we detected GATA-6 expression also in the one embryonal carcinoma studied, and in a majority of nonmalignant pediatric GCT (i.e. mature and immature teratomas). Within nonmalignant teratomas, GATA-6 expression was seen in gut and respiratory type epithelium, tissues known to express this transcription factor during normal development $(5,16-21)$, and in immature and mature neural tissues.

We also found that GATA-6 is expressed in sebocytes, an ectodermal derivative, in both mature teratomas and the normal mouse skin. Expression of GATA factors in mammalian skin has not been shown before, but, in Caenorhabditis elegans, the GATA factors ELT-1 and ELT-3 are expressed in the skin. Of note, ELT-1 has been shown by gene disruption to be essential for ectoderm development $(22,23)$. Further differentiation of 
the epidermal cells of this nematode to seam cells requires two other GATA factors, ELT-5 and ELT-6 (24). The function of GATA-6 in skin is unknown. In mammals, sebocytes have been shown to regulate androgen homeostasis in the human skin $(25)$ and GATA-6 is expressed in ovary $(8,26,27)$, testis (28), and adrenal gland (29), all of which are also involved in androgen metabolism.

The current results suggest that the same GATA-6-driven transcriptional mechanisms are involved in the normal embryonic development as well as in the differentiation of various tissues in teratomas. GATA- 6 is, however, normally not expressed in immature neural tissue $(5,16,26)$. In these tumors, the expression of GATA- 6 might even contribute to the failure of maturation. In the Xenopus embryos, an excess of GATA-6 expression blocks differentiation of the heart by possibly maintaining the cells in the precursor state (30). On the other hand, GATA-6 expression has been shown to be down-regulated in response to mitogen activation (26), and to be able to promote the quiescent phenotype of the vascular smooth muscle cells (31). The expression of GATA-6 also correlates with the cessation of proliferation in the smooth muscle cells of the developing kidney $(32,33)$. Thus, if the presence of this factor in tumor cells implicates lower proliferation activity, it might be a marker for good prognosis in these tumors. Larger quantities of GCT have to be, however, studied to explore the prognostic significance of GATA-6 expression in human tumors. Ultimately, GATA-6, as well as GATA-4, may offer new diagnostic tools to complement classical markers such as AFP in evaluating these neoplasms.

Acknowledgments. The authors thank Dr. Hannu Jalanko for critical reading of the manuscript. We also thank Ms. Ritva Löfman and Ms. Hannele Niemi for their help with the immunohistochemistry.

\section{REFERENCES}

1. Heikinheimo M, Wilson DB 2002 Germ cell tumors. In: Rudolph C, Rudolph A, Hostetter M, Lister G, Siegel N (eds) Rudolph's Paediatrics. McGraw-Hill, New York, pp 1622-1624

2. Wylie C 1999 Germ cells. Cell 96:165-174

3. Teilum G, Albrechtsen R, Norgaard-Pedersen B 1975 The histogenetic-embryologic basis for reappearance of alpha-fetoprotein in endodermal sinus tumors (yolk sac tumors) and teratomas. Acta Pathol Microbiol Scand [A] 83:80-86

4. Arceci RJ, King AA, Simon MC, Orkin SH, Wilson DB 1993 Mouse GATA-4: a retinoic acid-inducible GATA-binding transcription factor expressed in endodermally derived tissues and heart. Mol Cell Biol 13:2235-2246

5. Morrisey EE, Ip HS, Lu MM, Parmacek MS 1996 GATA-6: a zinc finger transcription factor that is expressed in multiple cell lineages derived from lateral mesoderm. Dev Biol 177:309-322

6. Koutsourakis M, Langeveld A, Patient R, Beddington R, Grosveld F 1999 The transcription factor GATA6 is essential for early extraembryonic development. Development 126:723-732

7. Morrisey EE, Tang Z, Sigrist K, Lu MM, Jiang F, Ip HS, Parmacek MS 1998 GATA6 regulates HNF4 and is required for differentiation of visceral endoderm in the mouse embryo. Genes Dev 12:3579-3590

8. Heikinheimo M, Ermolaeva M, Bielinska M, Rahman NA, Narita N, Huhtaniemi IT, Tapanainen JS, Wilson DB 1997 Expression and hormonal regulation of transcription factors GATA-4 and GATA-6 in the mouse ovary. Endocrinology 138:3505-3514
9. Kiiveri S, Liu J, Westerholm-Ormio M, Narita N, Wilson DB, Voutilainen R, Heikinheimo M 2002 Differential expression of GATA-4 and GATA-6 in fetal and adult mouse and human adrenal tissue. Endocrinology 143:3136-3143

10. Siltanen S, Anttonen M, Heikkila P, Narita N, Laitinen M, Ritvos O, Wilson DB, Heikinheimo M 1999 Transcription factor GATA-4 is expressed in pediatric yolk sac tumors. Am J Pathol 155:1823-1829

11. Soudais C, Bielinska M, Heikinheimo M, MacArthur CA, Narita N, Saffitz JE, Simon MC, Leiden JM, Wilson DB 1995 Targeted mutagenesis of the transcription factor GATA-4 gene in mouse embryonic stem cells disrupts visceral endoderm differentiation in vitro. Development 121:3877-3888

12. Bielinska M, Wilson DB 1997 Induction of yolk sac endoderm in GATA-4-deficient embryoid bodies by retinoic acid. Mech Dev 65:43-54

13. Kuo CT, Morrisey EE, Anandappa R, Sigrist K, Lu MM, Parmacek MS, Soudais C, Leiden JM 1997 GATA4 transcription factor is required for ventral morphogenesis and heart tube formation. Genes Dev 11:1048-1060

14. Molkentin JD, Lin Q, Duncan SA, Olson EN 1997 Requirement of the transcription factor GATA4 for heart tube formation and ventral morphogenesis. Genes Dev 11:1061-1072

15. Fujikura J, Yamato E, Yonemura S, Hosoda K, Masui S, Nakao K, Miyazaki Ji J, Niwa H 2002 Differentiation of embryonic stem cells is induced by GATA factors. Genes Dev 16:784-789

16. Narita N, Heikinheimo M, Bielinska M, White RA, Wilson DB 1996 The gene for transcription factor GATA-6 resides on mouse chromosome 18 and is expressed in myocardium and vascular smooth muscle. Genomics 36:345-348

17. Gao X, Sedgwick T, Shi YB, Evans T 1998 Distinct functions are implicated for the GATA-4, -5 , and -6 transcription factors in the regulation of intestine epithelial cell differentiation. Mol Cell Biol 18:2901-2911

18. Huggon IC, Davies A, Gove C, Moscoso G, Moniz C, Foss Y, Farzaneh F, Towner P 1997 Molecular cloning of human GATA-6 DNA binding protein: high levels of expression in heart and gut. Biochim Biophys Acta 1353:98-102

19. Bruno MD, Korfhagen TR, Liu C, Morrisey EE, Whitsett JA 2000 GATA-6 activates transcription of surfactant protein A. J Biol Chem 275:1043-1049

20. Keijzer R, van Tuyl M, Meijers C, Post M, Tibboel D, Grosveld F, Koutsourakis M 2001 The transcription factor GATA6 is essential for branching morphogenesis and epithelial cell differentiation during fetal pulmonary development. Development 128:503-511

21. Yang H, Lu MM, Zhang L, Whitsett JA, Morrisey EE 2002 GATA6 regulates differentiation of distal lung epithelium. Development 129:2233-2246

22. Gilleard JS, Shafi Y, Barry JD, McGhee JD 1999 ELT-3: a Caenorhabditis elegans GATA factor expressed in the embryonic epidermis during morphogenesis. Dev Biol 208:265-280

23. Gilleard JS, McGhee JD 2001 Activation of hypodermal differentiation in the Caenorhabditis elegans embryo by GATA transcription factors ELT-1 and ELT-3. Mol Cell Biol 21:2533-2544

24. Koh K, Rothman JH 2001 ELT-5 and ELT-6 are required continuously to regulate epidermal seam cell differentiation and cell fusion in C. elegans. Development 128:2867-2880

25. Fritsch M, Orfanos CE, Zouboulis CC 2001 Sebocytes are the key regulators of androgen homeostasis in human skin. J Invest Dermatol 116:793-800

26. Suzuki E, Evans T, Lowry J, Truong L, Bell DW, Testa JR, Walsh K 1996 The human GATA-6 gene: structure, chromosomal location, and regulation of expression by tissue-specific and mitogen-responsive signals. Genomics 38:283-290

27. Laitinen MP, Anttonen M, Ketola I, Wilson DB, Ritvos O, Butzow R, Heikinheimo M 2000 Transcription factors GATA-4 and GATA-6 and a GATA family cofactor, FOG-2, are expressed in human ovary and sex cord-derived ovarian tumors. J Clin Endocrinol Metab 85:3476-3483

28. Ketola I, Rahman N, Toppari J, Bielinska M, Porter-Tinge SB, Tapanainen JS, Huhtaniemi IT, Wilson DB, Heikinheimo M 1999 Expression and regulation of transcription factors GATA-4 and GATA-6 in developing mouse testis. Endocrinology 140:1470-1480

29. Kiiveri S, Siltanen S, Rahman N, Bielinska M, Lehto VP, Huhtaniemi IT, Muglia LJ, Wilson DB, Heikinheimo M 1999 Reciprocal changes in the expression of transcription factors GATA-4 and GATA-6 accompany adrenocortical tumorigenesis in mice and humans. Mol Med 5:490-501

30. Gove C, Walmsley M, Nijjar S, Bertwistle D, Guille M, Partington G, Bomford A, Patient R 1997 Over-expression of GATA-6 in Xenopus embryos blocks differentiation of heart precursors. EMBO J 16:355-368

31. Perlman H, Suzuki E, Simonson M, Smith RC, Walsh K 1998 GATA-6 induces p21(Cip1) expression and G1 cell cycle arrest. J Biol Chem 273:13713-13718

32. Morrisey EE 2000 GATA-6: the proliferation stops here: cell proliferation in glomerular mesangial and vascular smooth muscle cells. Circ Res 87:638-640

33. Nagata D, Suzuki E, Nishimatsu H, Yoshizumi M, Mano T, Walsh K, Sata M, Kakoki M, Goto A, Omata M, Hirata Y 2000 Cyclin A downregulation and p21(cip1) upregulation correlate with GATA-6-induced growth arrest in glomerular mesangial cells. Circ Res 87:699-704 